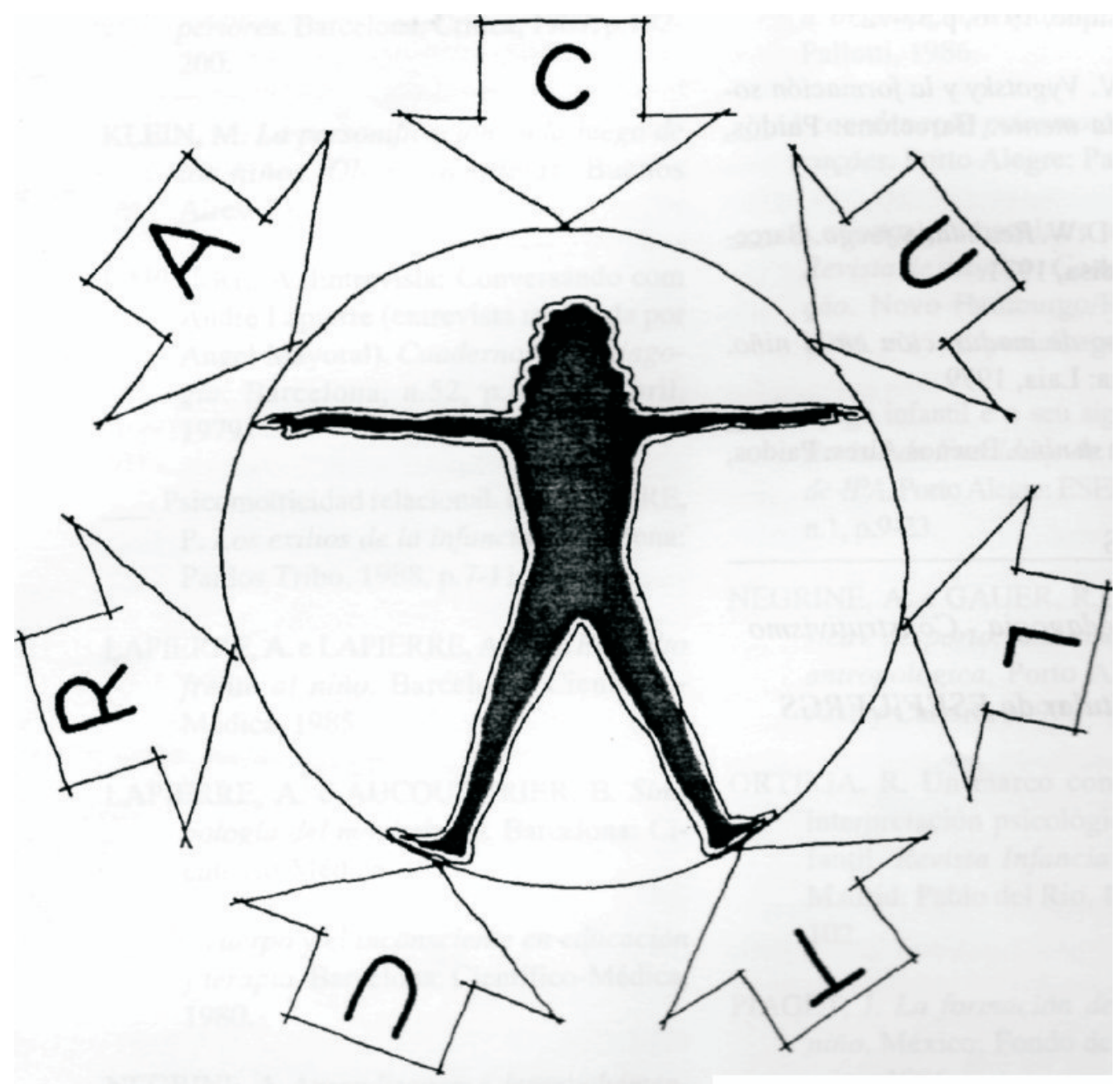

Orsignificados do corpo wa cultura e as im-

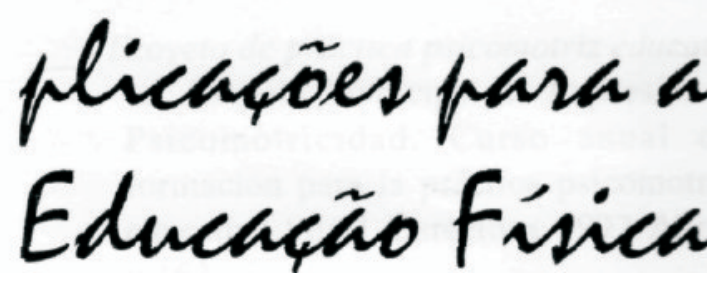

$\mathrm{Na}$ área da educação física fala-se muito, atualmente, sobre o corpo. Juntamente com esse substantivo, imprime-se uma série de adjetivos. Podemos aqui citar alguns: esbelto, saudável, bonito, sensual, livre, flácido, feio, reprimido, firme, mole, natural, holístico, moderno, consciente, inteiro, repugnante, prazeroso, gordo, magro, etc. Os profissionais da educação física trabalham com o ser humano sobre e através do seu corpo e lidam, por extensão, com os adjetivos impressos no corpo. Por isso, torna-se importante a reflexão sobre o tema.

Gostaríamos, inicialmente, de colocar algumas questões: Como definir um corpo esbelto? Como definir um corpo bonito, ou um corpo atraente, ou um corpo consciente? Como saber se o corpo já chegou ao estágio de liberdade tão sonhado? O que dizer, então, de um corpo feminino flácido, gordo, considerado deselegante nos dias de hoje, mas que era, há

\title{
Jocimar Daolio*
}


não muito tempo, considerado sensual e inspirava pintores renomados? O que dizer do conceito de saúde, associado antigamente a um corpo robusto, até mesmo gordo, c atualmente relacionado a um corpo magro? (Como se magro fosse sempre sinônimo de saudável!) E o corpo já não tão jovem, sobre o qual são impostos uma série de "consertos" e "reparos" para parecer (não para ser) novo, tais como plásticas, cremes anti-rugas, dietas rejuvenescedoras, ginásticas, esportes? Quem define esses atributos a respeito do corpo? Quem determina os critérios para se classificar o corpo num ou noutro grupo?

Para discutir com mais profundidade estas questões, estamos utilizando um referencial cultural. Não podemos imaginar um ser humano que não seja fruto da cultura e também não podemos imaginar um corpo natural. Portanto, qualquer adjetivo que se associe ao corpo é fruto de uma dinâmica cultural particular, e só faz sentido num grupo específico. O homem só chegou ao seu estágio aluai de desenvolvimento devido a um processo cultural de apropriação de comportamentos e atitudes que, inclusive, foram transformando o seu componente biológico. Não é possível desvincular o homem da cultura. O que o diferencia de outros animais, principalmente, é a sua capacidade de produzir cultura. Cultura essa que não é um ornamento, um algo a mais que se sobrepôs à natureza animal. A cultura foi a própria condição de sobrevivência da espécie. Portanto, podese dizer que a natureza do homem é ser um ser cultural \{GEERTZ, 1978).

Infelizmente, no meio acadêmico e profissional da educação física, essa problemática ainda não é compreendida no âmbito de um conhecimento antropológico. A ênfase na formação profissional em educação física ainda se refere ao homem e ao seu corpo como entidades primordialmente biológicas.' Temos ouvido comentários sobre o corpo que embutem uma noção que separa a natureza da cultura. Quando se defende a procura por um corpo natural, está se falando que é possível encontrar um corpo pré-cultural, ou que seja imune à cultura. Quando se fala do corpo livre, parece que se busca um corpo que não seja escravizado ou moldado pelas regras sociais. Ouvimos até certos excessos como "liberar o lado animal do corpo". Como se o corpo e o homem não fossem eminentemente culturais. Como se se quisesse achar um corpo ainda não atingido pela cultura ou anterior a ela.

O corpo é uma síntese da cultura, porque expressa elementos específicos da sociedade da qual faz parte. O homem, através do seu corpo, vai assimilando e se apropriando dos valores, normas e costumes sociais, num processo de inCORPOração (a palavra é significativa). Mais do que um aprendizado intelectual, o indivíduo adquire um conteúdo cultural, que se instala no seu corpo, no conjunto de suas expressões.

Cada gesto que fazemos, a forma como nos sentamos, a maneira como caminhamos, os costumes com o corpo da gestante (a mensagem hoje é que ela se movimente, ao contrário de poucos anos atrás), os cuidados com o bebé... tudo é específico de uma determinada cultura, que não é melhor nem pior que qualquer outra. A forma de chutar, os cuidados higiênicos com o corpo, os esportes que se praticam numa determinada época, num determinado local, são influenciados pela cultura. As brincadeiras, os tipos de ginástica, os cuidados estéticos com o corpo... enfim, tudo é influenciado pela cultura. Numa multidão, pode-se notar certos comportamentos corporais comuns, que caracterizam e padronizam um determinado povo. Aliás, como relata RODRIGUES (1987), pode-se reconhecer um brasileiro num outro país pela sua forma de andar e gesticular, sua postura, seus movimentos corporais. Duas seleções de voleibol, jogando com as mesmas regras e técnicas, e com sistemas táticos similares, possuem estilos diferentes, um jeito característico de praticar o voleibol ou o futebol, que reflete tradições culturais distintas.

Ao se pensar o corpo, pode-se incorrer no erro de encará-lo como puramente biológico, um patrimônio universal, já que homens
A cultura foi a própria condição de sobrevivência da espécie. Portanto, pode-se dizer que a natureza do homem é ser um ser cultural. 
de nacionalidades diferentes apresentam semelhanças físicas. Entretanto, para além das semelhanças ou diferenças físicas, existe um conjunto de significados que cada sociedade escreve nos corpos dos seus membros ao longo do tempo, significados estes que definem o que é corpo de maneiras variadas.

Estamos falando das técnicas corporais, que Marcel Mauss, um antropólogo francês, definiu, já na década de 30 , como as maneiras de se comportar de cada sociedade. Mauss considerou os gestos e os movimentos corporais como técnicas próprias da cultura, passíveis de transmissão através das gerações e imbuídas de significados específicos. Técnicas corporais culturais, porque toda técnica é um hábito tradicional, que passa de pai para filho, de geração para geração. Segundo ele, só é possível falar em técnica, por ser cultural (MAUSS, 1974, v.2).

KOFES (1985), reforçando esse ponto de vista, afirma que o corpo é expressão da cultura, portanto cada cultura vai se expressar através de diferentes corpos, porque se expressa diferentemente enquanto cultura. É nesse contexto que DAMATTA (1987) pôde afirmar que existem tantos corpos quanto há sociedades.

O corpo é uma síntese da cultura, porque expressa elementos específicos da sociedade da qual faz parte.
O corpo humano não é um dado puramente biológico sobre o qual a cultura impinge especificidades. O corpo é fruto da interação natureza/cultura. Conceber o corpo como meramente biológico é pensá-lo - explícita ou implicitamente - como natural e, consequentemente, entender a natureza do homem como anterior ou pré-requisito da cultura. SANTOS (1990) critica os que propõem a volta a um suposto corpo natural não atingido pela cultura. Segundo ele, não se pode esquecer da natureza necessariamente social de uso do corpo, sendo possível somente pensar em novos usos do corpo, já que a cultura é passível de reinvenções e recriações.

RODRIGUES afirma que "(...) nenhuma prática se realiza sobre o corpo sem que tenha, a suportá-la, um sentido genérico ou específico" (1986, p.64). É justamente esse sentido es- pecífico que incide sobre toda e qualquer atividade corporal o que impede de pensar o corpo como um dado biológico. O que define corpo é o seu significado, o fato dele ser produto da cultura, ser construído diferentemente por cada sociedade, e não as suas semelhanças biológicas universais.

Fica evidente, portanto, que o conjunto de posturas e movimentos corporais representam valores e princípios culturais. Conseqüentemente, atuar no corpo implica em atuar sobre a sociedade na qual este corpo está inserido. Todas as práticas institucionais que envolvem o corpo humano - e a Educação Física faz parte delas - sejam elas educativas, recreativas, reabilitadoras ou expressivas, devem ser pensadas neste contexto, a fim de que não se conceba sua realização de forma reducionista, mas se considere o homem como sujeito da vida social.

Entretanto, os profissionais de educação física, cotidianamente, utilizam o termo técnica não no sentido que o fez Mareei Mauss, de um ato cultural, mas como um conjunto de movimentos considerados sempre correios, precisos, melhores do que outros. Nas aulas, o aluno melhor é aquele que chega mais próximo da técnica considerada certa pelo professor. Falamos de um andar correto, de um correr adequado, de uma postura melhor, de um corpo perfeito, desconsiderando, muitas vezes, que os movimentos são também culturais. A especificidade de raça humana é se apresentar e se dispor através de grandes diferenças. Embora se apresentando diferentemente, os homens não perdem a condição de membros da espécie humana.

Acreditamos já ser possível pensar no duplo sentido do termo Cultura Corporal. No primeiro, que rebatemos, se pressupõe uma única técnica sobre o corpo; a palavra cultura acaba sendo usada como sinônimo de treinamento, adestramento do corpo. É neste sentido que termos como culturismo e fisioculturismo são utilizados, constituindo-se em mais um discurso sobre o corpo, apenas uma das técnicas sobre ele colocadas. Não a única, nem a melhor. 
O sentido de Cultura Corporal que utilizamos parte da definição ampla de Cultura e diz respeito ao conjunto de movimentos e hábitos corporais de um grupo específico. E nessa concepção que se pode afirmar que não existe um discurso puro do corpo. $\mathrm{O}$ corpo não fala sobre o corpo, será apenas mais um discurso sobre o corpo. Em uma dada época, num determinado contexto, um discurso prevalece sobre o outro. Em outros termos, não há corpo livre, mas discursos sobre corpo livre; não há corpo consciente, mas discursos sobre corpo consciente. KOFES (1985) discutiu de forma pertinente esta questão do discurso do corpo $\mathrm{X}$ discurso sobre o corpo, afirmando que é necessário manter as seguintes indagações quando se aborda esse tema: "(...) o que a sociedade está afirmando dos corpos? que corpos? que individualidades? que sociedades?"(p.57).

Na Educação Física brasileira, atualmente, começa a ser utilizado o termo Cultura Corporal em sentidos próximos daquele por nós defendido. No livro Metodologia do Ensino de Educação Física (BRACHT, V. et al. 1992, p.39) encontramos a seguinte referência: "(...) a materialidade corpórea foi historicamente construída e, portanto, existe uma cultura corporal, resultado de conhecimentos socialmente produzidos e historicamente acumulados pela humanidade (...)". PEREIRA (1988) fala de uma cultura física como "(...) toda a parcela da cultura universal que envolve o exercício físico, como a educação física, a ginástica, o treinamento desportivo, a recreação físico-ativa, a dança etc."(p.20). Betti (1992) lembra que FEIO (s.d.) $)^{2}$ já se referiu a uma cultura física como parte de uma cultura geral, que contempla as conquistas materiais e espirituais relacionadas com os interesses físico-culturais da sociedade.

A pesquisa antropológica, embora incipiente na área, pode ser útil na medida em que se preocupar com os discursos sobre o corpo, ou, melhor dizendo, com as representações sociais que suportam as várias concepções de corpo, concepções essas que justificam e orientam determinadas práticas profissionais num grupo específico e numa dada época. Qual é a representação de corpo que os pro- fessores de Educação Física possuem? Que conjunto de significados a respeito do corpo possuem os freqüentadores de academias de ginástica? Qual é o universo simbólico a respeito do corpo que técnicos esportivos possuem? Essas perguntas somente agora começam a ser formuladas, ainda não sendo possível respondê-las de forma mais profunda.

A intenção destas reflexões foi somente a de alertar que os profissionais de educação física, por trabalharem com o homem através do seu corpo, estão trabalhando com a cultura impressa nesse corpo e expressa por ele. Portanto, mexer no corpo é mexer na sociedade da qual esse corpo faz parte. O profissional pode fazer isso de forma explícita, atento para as conseqüências do seu trabalho, ou de forma implícita e inconseqüente. Parece-nos evidente tentarmos estar atentos e conscientes em relação ao papel do corpo na cultura.

\section{REFERÊNCIAS BIBLIOGRÁFICAS}

BETTI, M. Ensino de primeiro e segundo graus: educação física para quê? Revista Brasileira de Ciências do Esporte, v.13, n.2, p.282-7,1992.

BRACHT, V. et al. Metodologia do ensino de educação fisica. São Paulo, Cortez, 1992.

DAMATTA, R. O corpo brasileiro. In: STROZENBERG, I.(org.). De corpo e alma. Rio de Janeiro, Comunicação Contemporânea, 1987.

GEERTZ, C. A interpretação das culturas. Rio de Janeiro, Zahar, 1978.

KOFES, S. E sobre o corpo, não é o próprio corpo que fala? Ou o discurso desse corpo sobre o qual se fala. In: BRUHNS, H.T.(org.). Conversando sobre o corpo. Campinas, Papirus, 1985.

MAUSS, M. Sociologia e antropologia. São Paulo, EPU/EDUSP, 1974. 2v.

PEREIRA, F.M. Dialética da cultura física: introdução à crítica da educação física, 
do esporte e da recreação. São Paulo, Ícone, 1988.

RODRIGUES, J.C. Tabu do corpo. 4.ed. Rio de Janeiro, Dois Pontos, 1986.

. 0 corpo liberado? In: STROZENBERG, I.(org. \}. De corpo e alma. Rio de Janeiro, Comunicação Contemporânea, 1987.

SANTOS, F.J.A. dos. Considerações sobre a "corpolatria". Motrivivência, v .2, n.3, p.534,1990 .

\section{NOTAS}

${ }^{1}$ Não pretendemos, nesse trabalho, discutir as causas e as conseqüências do processo de bíologização da educação física. Recomendamos a leitura de nossa Dissertação de Mestrado, intitulada "A Representação do Trabalho do Professor de Educação Física na Escola: Do Corpo Matéria-prirna ao Corpo Cidadão", Escola de Educação Física da USO. 1992.

${ }^{2}$ Feio, Noronha. Desporto e política: ensaios para sua compreensão. Lisboa Compendium. s.d.

UNITERMOS

Educação Física - Cultura - Corpo

* Professor da Faculdade de Educação Física da UNICAMP 